\title{
Abdominal Physical Signs of Inspection and Medical Eponyms
}

\author{
Vaibhav Rastogi, MD; Devina Singh, MD; Halil Tekiner, PhD; Fan Ye, MD; \\ Joseph J. Mazza, MD; and Steven H. Yale, MD
}

\begin{abstract}
Background: An eponym in clinical medicine is an honorific term ascribed to a person(s) who may have initially discovered or described a device, procedure, anatomical part, treatment, disease, symptom, syndrome, or sign found on physical examination. Signs, although often lacking sufficient sensitivity and specificity, assist in some cases to differentiate and diagnose disease. With the advent of advanced technological tools in radiological imaging and diagnostic testing, the importance of inspection, the initial steps taught during the physical examination, is often overlooked or given only cursory attention. Nevertheless, in the era of evidence-based and cost-effective medicine, it becomes compelling, and we contend that a meticulously performed history and physical examination, applying the basic tenets of inspection, remains paramount prior to obtaining appropriate diagnostic tests.
\end{abstract}

Data Sources: PubMed, Medline, online Internet word searches and bibliographies from source text and textbooks. PubMed was searched using the Medical Subject Heading (MeSH) of the name of the eponyms and text words associated with the sign.

Conclusions: We describe the historical aspect, clinical application, and performance of medical eponymous signs of inspection found on physical examination during the 18th to 20th centuries.

Keywords: Abdomen; Eponyms; Inspection; Physical Examination; Signs; History of Medicine

$\mathrm{P}$ hysical signs associated with medical eponyms are commonly encountered in clinical medicine and typically occur in conjunction with some degree of pathology recognized on physical examination, although their sensitivity and specificity in some cases is often unknown. A number of limitations associated with medical eponyms are commonly encountered. First, the method for performing a particular test described in the original work may not have been accurately translated from the native language to the English language, causing incorrect performance. ${ }^{1}$ Secondly, although there may be significant contributions from others in the discovery of a new condition or physical sign, the eponym often honors only one person, typically the one who applied it or more thoroughly described it in clinical medicine. ${ }^{2}$ Third, the name may be misspelled, and fourth, historical aspects and reports from the original description may not be accessible, since it may have been written in a monograph or presented at a conference.

Inspection is an important and often-overlooked aspect of the physical examination. The medical term is derived from the Latin inspectio, to look. It was Hippocraties (460 BC-370 $\mathrm{BC})$, a Greek physician and founder of modern medicine, who made some of the earliest recorded descriptions of patients with acute and progressive disease. ${ }^{3}$ The Book of
Corresponding Author: Steven H. Yale, MD, MACP, University of Central Florida College of Medicine, 6850 Lake Nona Blvd, Orlando, FL 32827

Email: steven.yale.md@gmail.com
Received: March 15, 2018

Revised: March 11, 2019

Accepted: March 18, 2019 


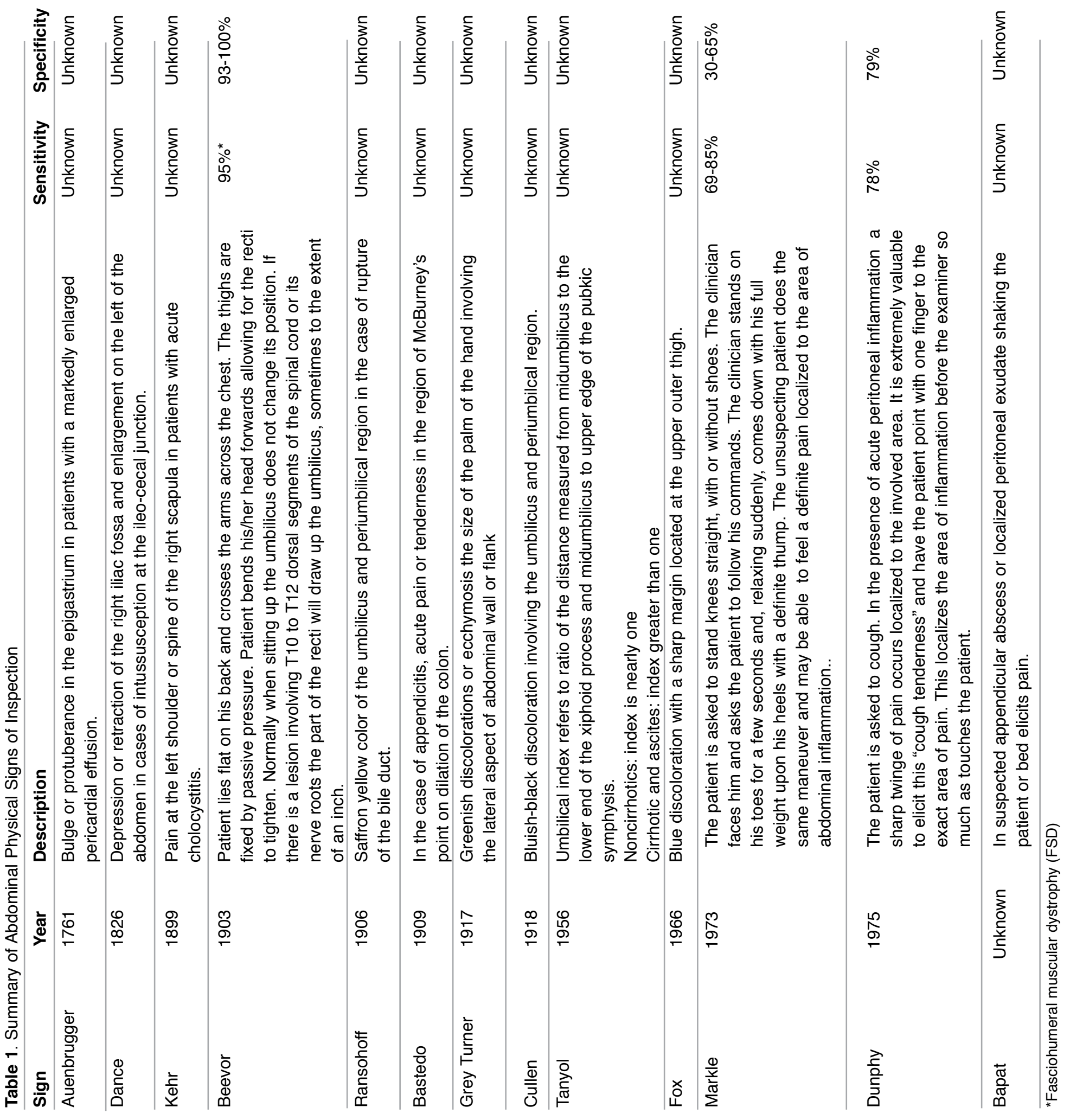


Prognostics described his observation of the appearance of a patient with acute disease,

A sharp nose, hollow eyes, temples collapsed, the brows

knit, ears cold and contracted, and their lobes inverted, the forehead hard, dry, and tense, the whole countenance pallid, greenish, black, livid or of a leaden hue. ${ }^{4}$ (emphasis added)

This finding is recognized by the eponymous sign "Hippocratic facies".

Inspection of the abdomen involves observing the abdominal wall for ecchymosis, bulges, depression, contours, abnormal movement and locations of the umbilicus, and the appearance of the patient at rest and with movements. These clinical cues, expressed as medical eponyms, provide important information that may be useful in identifying the disease process, narrowing the differential diagnosis, and in some cases identifying the source of disease. The goal of this paper is to briefly highlight important historical aspects of physicians who described the physical signs of abdominal inspection, report the sign, and determine the sign's validity in current clinical practice. The signs are presented sequentially based on the year they were first reported (Table 1).

\section{Data Sources}

PubMed, Medline, online Internet word searches, and bibliographies from source text and textbooks were used. PubMed was searched using the Medical Subject Heading (MeSH) of the name of the eponyms and text words associated with the sign.

\section{Auenbrugger Sign}

Joseph Leopold Auenbrugger (Leopold von Auenbrugger) (1722-1809) was born at Graz in Styria, lower Austria on November 19, 1722..$^{5}$ After completing his medical education in Vienna in 1752, he practiced at the Spanish Military Hospital and Holy Trinity Hospital in Vienna until 1762, achieving the rank of Attending Physician. ${ }^{6}$ One of his most significant contributions to medicine was the use of percussion as a diagnostic technique, ${ }^{7}$ described in his book Inventum Novum Ex Percussione Thoracis Humani Ut Signo Abstrusos Interni Pectoris Morbos Detegendi (New Invention to Detect the Diseases Hidden Deep Inside the Chest) in $1761 .{ }^{8} \mathrm{He}$ recognized that sounds are explained by reference to corresponding physical states; ie, to the presence or absence of air in the part percussed. Auenbrugger described percussion of the chest in health and in the disease state, recorded the results, and urged physicians to adopt this technique. ${ }^{6}$ This was an important finding, since during that time diseases were often grouped together such that there was no distinction between asthma, pneumonia, pleurisy, or heart failure. The medical community, however, did not initially embrace this finding until Jean-Nicholas Corvistat (1755-1821), senior physician to Napoleon I and leader of the medical profession in France, translated Inventum Novum into French, modifying and acknowledging Auenbrugger's original work.
In Sir John Forbe's (1787-1861) translation of Inventum Novum, Auenbrugger wrote under the twelfth observation of dropsy of the chest "Swelling of the abdomen, more especially the Epigastrium, and particularly in that point on which the incumbent water gravitates." 8 (p.399) In the section on signs of the "Dropsy of the Pericardium (hydropericardium) XLVI", Auenbrugger wrote:

Almost all the symptoms which have already been enumerated as accompanying dropsy of the chest generally accompany this species also; in addition to these, however, I have observed the following specific signs of the dropsy of the pericardium: The sound in the cardiac region, which I have already stated (III.2.3) to be naturally more obscure than in other parts of the chest; is now as completely deadened as if the percussion were applied to a fleshy limb. A swelling is perceived in the praecordia, which can readily be distinguished by its superior resistance, from the stomach distended by flatus. ${ }^{8}$ (p.401, emphasis added)

This sign, thus, refers to the presence of a visible bulge or prominence in the epigastrium in patients with a markedly enlarged pericardial effusion. ${ }^{9,10}$ We are unaware of any study that evaluated the sensitivity or specificity of this sign.

\section{Dance Sign}

Jean Baptiste Hippolyte Dance (1797-1832) was born in Saint-Pal-de Chalencon, France. He was a student at ancient École pratique and received his doctor of medicine degree in 1826 in Paris. ${ }^{11}$ He was a member of the Anatomical Society of Paris in 1827, a physician to the Hôpital Cochin and Bureau de charité de bienfaisance in 1830, and taught in the clinic of Hôtel-Dieu in $1832 .^{11}$

Jean Baptiste Hippolyte Dance (1826) published as a memoire in the Journal d'Anatomie et de Physiologie Pathologique (Journal of Anatomy and Pathological Physiology) the observation:

The cecum and the colon had been so displaced that they had come to lodge in the sigmoid curve of the colon. In these three cases, the form of the abdomen presented something peculiar. The absence of the ascending cecum and ascending colon towards the right side of the abdomen caused a certain depression in this side, while on the left there was a longitudinal enlargement, a tumor more or less voluminous produced by the mass of intussusception. ${ }^{12(p .211)}$

Thus, the sign is a visual depression of the right iliac fossa and voluminous enlargement on the left of the abdomen, a condition most commonly found in infants. The etiology is due to intussusception of the bowel. It is considered pathognomonic for intussception in children and found in $85 \%$ of cases. ${ }^{13}$ Sty et al reported, 'The 'Dance Sign' is an uncommon but reliable observation found on physical examination in patients with intussusception."14(emphasis added) 


\section{Kehr Sign}

Johannes Otto Kehr, or Hanes Kehr, (1862-1916) was born in Waltershausen, Thuringia, Germany and received his medical training in Freiburg, Jena, Halle, and Berlin. ${ }^{15}$ After graduating from medical school in 1885, he worked with various wellknown surgeons of his time, including Dr. Theodor Billroth, and earned the Specialist for Surgery and Orthopedics degree in 1888. Thereafter, he performed surgery in a private clinic in Halberstadt, earning the titles Professor in 1895 and Privy Councillor in 1905, later moving to Berlin in $1910 .{ }^{15}$ In 1913 , he published his two-volume book entitled Die Praxis der Gallenwege-Chirurgie in Wort and Bild (The Practice of Biliary Tract Surgery in Words and Pictures). ${ }^{16}$ His significant contributions were in the surgical management of the gall bladder and biliary diseases.

Kehr sign has traditionally been described as pain referred to the left shoulder on gentle palpation of the abdomen when the patient is lying down with legs elevated. It is classically associated with splenic rupture. This traditional eponym assigned to Dr. Kehr has been challenged due to the lack of compelling information ascribed to his work. ${ }^{17} \mathrm{Kehr}$, in his 1899 book entitled Anleitung zur Erlernung der Diagnostik der einzelnen Formen der Gallensteinkrankheit; auf Grund eigener, bei 433 Gallensteinlaparotomien Gewonnener Erfahrungen für den praktischen Arzt zusammengestellt (Introduction to the Differential Diagnosis of the Separate Forms of Gallstone Disease based upon his own experience gained in 433 laparotomies for gallstone), described a patient with recurrent cholecystitis or cholangitis (accompanying inflammatory jaundice), adhesive peritonitis, and adhesions between the gallbladder and omentum or colon, and " [...] with this several attacks of colic and inflammation in the leftshoulder-joint."18 (p.260, emphasis added) He also reported that "The pain of gallstone colic is more to the right and localized in the region of the gall-bladder whence it frequently radiates to the back and to the right shoulder blade and breast." 18 (p. 71, emphasis added) Thus, the focus of his work was on disease of the gallbladder and not of the spleen.

A study by Lowenfels et $\mathrm{al}^{19}$ showed that nine out of ten patients with splenic rupture had positive Kehr sign at presentation. Studies have shown this sign in patients with splenic abscess, spontaneous phrenic artery rupture, infectious mononucleosis, and following colonoscopy. ${ }^{20-26}$ Irritation of the diaphragm by the abdominal contents, such as free blood, results in transmission of pain sensation through the phrenic nerve to the C3-C4 nerve roots. Supraclavicular nerve supplying the left shoulder shares the origin with phrenic nerve and, thus, pain is also referred to the left shoulder. ${ }^{19,20}$ There are no studies that defined the sensitivity or specificity of this sign.

\section{Beevor Sign}

Charles Edward Beevor (1854-1908) was born in London, received his medical training at the University College Hospital in London and his medical degree in 1881. Dr.
Beevor served as a Physician at Queen Square Hospital in 1883 and Great Northern Hospital in $1885 .{ }^{27,28} \mathrm{He}$ received a Fellowship from the Royal College of Physicians in 1888 and was President of the Neurological Society of the United Kingdom from 1907-1908. ${ }^{29}$ His greatest contributions to medicine included a description of the cerebral arterial supply and the diagnosis and localization of tumors of the brain.

Dr. Beevor reported at the Croonian Lectures in 1903, the method for testing the recti abdominis muscles as:

[t]he person lies flat on his back and crosses the arms of the chest, and the thighs are then fixed by passive pressure. It is then often sufficient for the person to bend the head forwards for the recti to tighten up sufficiently to be felt. ${ }^{30}$ (p.39, emphasis added)

He further stated:

I observed some years back a symptom which enables the investigator to tell if there is any weakness of the upper or lower parts of the recti. This symptom is the movement of the umbilicus. In health, in the movement of sitting up the umbilicus does not alter its position, but, if from a lesion of the lower part of the spinal cord or its nerves, the part of the recti will draw up the umbilicus, sometimes to the extent of an inch. As the abdominal wall at the level of the umbilicus is supplied by the tenth dorsal root, any marked elevation of the umbilicus in the act of sitting up would show a lesion between the tenth and twelfth dorsal segments of the cord, or the roots coming off from them. ${ }^{30}$ (p.40, emphasis added) Dr. Hugh T. Patrick (1910), Dr. Beevor's assistant, further commented on the direction of the umbilicus as "In some cases will get it obliquely, not only drawn upwards, as one of the muscles is paralyzed below, but sometimes obliquely to the right or left, which gives a clue to the side of the tumor." 31 (p.64, emphasis added) Lesions between T10 and T12 involving the roots or spinal cord as well as myopathic processes affecting the recti muscles cause a positive Beevor sign. ${ }^{32}$

Awebuch et $\mathrm{al}^{33}$ reported a positive Beevor sign in 27 of 30 patients (90\%) with fascioscapulohumeral muscular dystrophies (FSHD) and none in 40 patients with other neuromuscular disorders. Beevor sign was found in 19 of 20 (95\%) patients with FSHD and 2 of 28 controls. A 95\% sensitivity for Beevor sign was found in patients with FSHD. Additionally, a specificity of $93 \%$ and $100 \%$ was identified in the cohort with a variety of neuromuscular disease and controls without neurologic disease, respectively. ${ }^{34}$ In another study, Eger ${ }^{35}$ reported that Beevor sign was present in four of five $(85 \%)$ patients with FSHD. It has also been described in a patient with spinal cord vascular tumor at $\mathrm{T} 10,{ }^{36}$ spinal cord injury at or below T10, familial tubular aggregate myopathy, amyotrophic lateral sclerosis, ${ }^{34}$ and sporadic and hereditary inclusion body myositis. ${ }^{37-39}$

\section{Ransohoff Sign}

Joseph Louis Ransohoff (1880-1958) was born in Cincinnati, Ohio and received his medical degree from the University of Cincinnati in $1904 .{ }^{40}$ Dr. Ranshoff studied surgery in Vienna, 
Berlin, and London for 2 years and practiced surgery with his father, Dr. Joseph Ransohoff, who shared the same first name, in Cincinnati Ohio. ${ }^{41}$ Here he served as Professor of Clinical Surgery at Cincinnati University. ${ }^{42}$

Ransohoff described a preoperative finding in 1906 in a 53-year-old man with ruptured common bile duct and bile peritonitis as:

On inspection of the abdomen, attention was called to a marked jaundice of the umbilicus. The navel was of a distinct saffron-yellow color in strong contrast with the rest of the skin over the abdomen. It was the only evidence of jaundice. Tenderness was extremely marked over McBurney's point. ${ }^{43}$ (p.396, emphasis added)

During the operation he found:

With the opening of the peritoneum, there poured forth a quart or more of free bile mixed with serum. [...] After thoroughly removing with gauze sponges the free bile in the peritoneal cavity, it was evident that the flow of bile continued from the aperture behind the gastrohepatic ligament. The fat in the great omentum was very deeply stained with bile. By holding the latter aside and pressing the viscera, with gauze aprons to the left, a tear could be felt in the posterior wall of the common duct, through which the bile without question had escaped. ${ }^{43}$ (p.396)

In his description of the findings he writes:

I wish here to call attention to a sign which was referred to in the case of the ruptured duct before the incision was made, and one to which I believe attention has never before been directed. It is the localized jaundice of the umbilicus. Although a single case is not usually sufficient to warrant the assumption that something new has been observed, this feature was so marked that I can not refrain from believing that further observation will give to this localized jaundice some value as a sign of free bile in the peritoneal cavity. In the case presented, this feature gained in interest as the staining of the subperitoneal fat with bile was observed in the incision through the abdominal wall. The jaundice is probably the result of inhibition. It makes itself manifest first in the integument of the navel, because this part is thinner than the rest of the abdominal wall. It is possible, of course, that by reason of the anatomic relations of the round ligament of the liver to the transverse fissure there is a retrograde flow of bile through the lymphatics toward the navel, just as the caput medusa is produced in cirrhosis. ${ }^{43(\mathrm{p} .397)}$

This sign, thus, refers to the yellowish discoloration of the umbilicus and periumbilical region indicative of rupture of the bile duct. It represents a localized jaundice of the umbilicus; a sign of free bile in the peritoneal cavity. ${ }^{43}$ This is a rare finding, and we are not aware of any studies that have validated the sensitivity or specificity of this sign.

\section{Bastedo Sign}

Walter Arthur Bastedo (1873-1952) was born in Newmarket,
Ontario, Canada. He graduated from the College of Pharmacy of the City of New York and received his medical degree from Columbia University College of Physicians and Surgeons in New York in 1899. He was associated with St. Luke's Hospital and taught pharmacology at Columbia Medical School. ${ }^{44,45}$ In 1916 , he was appointed attending physician to the City Hospital and promoted to Associate physician at St. Luke Hospital. ${ }^{46}$ Bastedo served as Chairman of the Section of Pharmacology and Therapeutic Committee (1918-1919) and committee on revisions to the United States Pharmacopoeia, and Executive Committee (1919-1920) of the American Medical Association. ${ }^{47,48}$ In 1921, as faculty at Cornell University Medical College, he was elected officer of the New York Association for Medical Education. ${ }^{49}$ In 1929, he received the honorary degree of Doctor of Science from Columbia University and in 1934 the honorary degree of Master of Science from Philadelphia College of Pharmacy and Science. ${ }^{50}$

In 1909, Bastedo read before the Medical Society of the County of Richmond a method of dilation of the colon with air as a means to differentiate chronic appendicitis from other causes of right lower quadrant abdominal pain as follows:

"To dilate the colon a soft rubber rectal tube is inserted about twelve inches and air forced through it by means of an atomizer bulb. The introduction of the tube is facilitated if air is forced through it during its passage up the rectum. " 51 (p.108, emphasis added)

Bastedo reported:

Dilation of the colon, or attempt to dilate it, is useful in determining the following: rectal obstruction, [...] colon obstruction, [...] the location of the sigmoid flexure, [...] the location of the transverse colon and the condition of its muscle, [...] the location of the cecum, [...] the site of tumor or tender spot, the presence of chronic appendicitis. ${ }^{51}$ (p.108, emphasis added)

Furthermore:

In the routine examination of digestive patients by colon dilation, I noted, some three years ago, that acute pain or tenderness in the region of McBurney's point on dilation of the colon regularly meant appendicitis. I have now many cases in which the finding has been proved by operation, and in every case operated upon in which the sign was positive, a diseased appendix has been found. [...] In no operation cases with the sign negative was appendicitis found..$^{51}$ (p.110, emphasis added)

A positive sign is the presence of "[a]cute pain or tenderness in the region of McBurney's point on dilation of the colon regularly meant appendicitis" ${ }^{1}$ (p.110) C.W. Bischoff reported the results of this test in 37 patients undergoing laparotomy for abdominal pain and found that the sign was positive in 23 patients with chronic appendicitis. In 14 cases where the sign was negative, there was no evidence of chronic appendicitis. ${ }^{52}$ This result suggests that the sign may be useful for the diagnosis of chronic appendicitis, but further studies are required. Hertz (1913) reported: 
In my own experience, I have only obtained a positive Bastedo's sign in appendicitis, the appendix having always been found diseased at the subsequent operation, with the possible exception of one case, which is still too recent to form a judgment as to whether the removal of an apparently normal appendix will cause the symptoms to disappear. ${ }^{53}$ (emphasis added)

\section{Grey Turner Sign}

George Grey Turner (1877-1951), a British surgeon, was born in North Shields, a town in North East England, graduated from Newcastle Medical School of Durham University, and became Fellow of the Royal College of Surgeons in 1903. He served as Professor of Surgery at Newcastle until 1935 when he moved to Hammersmith Hospital to serve as the Foundation Chair of Surgery at the British Postgraduate Medical School from 1935 until 1946. ${ }^{54}$ In 1927, he was promoted Professor of Surgery at the University of Durham in $1927 .{ }^{55}$

Grey Turner described in his 1917 paper published in the British Journal of Surgery, "Local discoloration of the abdominal wall as a sign of acute pancreatitis" the findings that:

The tenderness over the gall-bladder region was very marked, and I now noticed two large discolored areas in the loins. They were about the size of the palm of the hand, slightly raised above the surface, and of a dirtygreenish colour. There was little oedema, with pitting on pressure, but there was no pain or tenderness. ${ }^{56}$ (p.394-395, emphasis added)

Thus, this sign refers to the bluish discolorations or ecchymosis of the lateral aspect of abdominal wall or flank. He believed it was caused by the spread of pancreatic secretions through the retroperitoneal tissues.

He also reported on a case he had seen in 1912 of a 54-yearold female with pancreatitis with the following finding in the periumbilical region:

I was at once struck by the appearance of the abdominal wall surrounding the umbilicus. In this neighbourhood there was an area of discoloration about 6 inches in diameter, of a bluish colour, very like the early postmortem staining seen on the abdominal wall, or the appearance of the skin in a late case of extravasation of urine. The area was slightly raised, and pitted on pressure. 56 (p.394, emphasis added $)$

He believed that the pancreatic secretions reached the umbilicus through the round ligament of the liver. It should be noted that this report of periumbilical ecchymosis predated Cullen's original paper.

Grey Turner sign is caused by the diffusion of blood from the anterior pararenal space to the lateral edge of the quadratus lumborum muscle, passing through a defect in the transversalis fascia that leads to the subcutaneous tissue within the abdominal wall muscle and flank. ${ }^{57,58}$ The limited extent of discoloration is explained by the corresponding attachment of the membranous superficial fascia to the deep external oblique aponeurosis. ${ }^{59}$

Grey Turner sign is found in a number of conditions associated with retroperitoneal or intra-abdominal bleeding such as a leaky abdominal aortic aneurysm, retroperitoneal bleeding caused by trauma, spontaneous hemorrhage of the abdominal wall after coughing, desmoid tumor of the rectus abdominis muscle, adrenal cyst, and intra-aortic balloon pump insertion. ${ }^{60-63}$ It can take 2-3 days for the appearance of Cullen and Grey Turner signs to appear, depending on the stage of red blood cell breakdown; the skin turns from green/ yellow to a purplish color. ${ }^{10}$ In a randomized, double blinded trial assessing the course of aprothinin and glucagon on acute pancreatitis in 257 patients, Grey Turner sign was observed in only two patients $(0.78 \%){ }^{64}$ Grey Turner and Cullen signs signify the presence of severe acute hemorrhagic pancreatitis, but they lack specificity for diagnosis. Individual presentations as well as co-existence of these signs are found in approximately $1 \%-3 \%$ of patients with acute pancreatitis. ${ }^{57,65}$ Hence, Grey Turner and Cullen (described in the next section) signs are rare and non-specific findings. The occurrence of one or both signs is associated with a mortality rate of $37 \% .{ }^{65}$ Early recognition of these signs may affect prognosis. $^{57}$

\section{Cullen Sign}

Thomas Stephen Cullen (1868-1953), a Canadian-American gynecologist, was born in Bridgewater, Ontario, Canada in 1868. He received his medical degree from Toronto University Medical School in $1890 .{ }^{15} \mathrm{He}$ was a fellow of the American Gynecological Society serving on the council from 1904 to 1914. At Johns Hopkins, he was appointed Professor of Clinical Gynecology in 1919 and Professor of Gynecology in 1932. ${ }^{66,67}$ His research interests included uterine cancer and ectopic pregnancy. He published the first manuscript describing the pathological and clinical aspects of endometrial hyperplasia. ${ }^{15}$ As described by Richard W. Te Linde, one of Dr. Cullen's greatest contributions to medicine was his role in establishing a school of art as applied to medicine at Johns Hopkins University. ${ }^{68}$

Cullen described at The American Gynecological Society and published in the American Journal of Obstetrics and Gynecology in 1918, "A new sign in ruptured extrauterine pregnancy" in a 38 -year-old female. ${ }^{69,70} \mathrm{He}$ reported that:

The umbilical region was bluish black, although she gave no history of injury. [...] He referred to a case reported by Ranshoff where a man, fifty-three years of age, had obscure abdominal symptoms. Jaundice of the umbilical region was soon noted and at operation rupture of the common duct was found and there was much free bile in the abdomen. Judging from the analogy the speaker naturally concluded that the bluish-black appearance of the umbilicus was due to intraabdominal hemorrhage, and the presence of the 
nodule to the side of the uterus clinched the diagnosis of extrauterine pregnancy. ${ }^{69}$ (emphasis added)

Thus, Culllen sign is recognized as a umbilical and periumbilical bluish discoloration or ecchymosis caused by blood and accompanied by superficial edema of the subcutaneous fatty tissue. It is of historic interest that Grey Turner described a case of umbilical ecchymosis in a 54-year-old female patient with pancreatic necrosis first seen in 1912 in his 1917 paper "Local discoloration of the abdominal wall as a sign of acute pancreatitis." 56

Cullen sign has been described in multiple conditions in addition to hemorrhagic pancreatitis such as perforated duodenal ulcer; ruptured ectopic pregnancy, ruptured abdominal aortic/iliac artery aneurysm, pancreatic or abdominal trauma, splenic rupture, biliary system rupture, percutaneous liver biopsy, hepatocellular carcinoma, and other causes of hemoperitoneum. ${ }^{71-76}$ The pathophysiology behind the appearance of this sign, using computerized tomography (CT), is caused by tracking of hemorrhagic fluid and pancreatic enzymes towards the umbilicus from the retroperitoneum along the gastrohepatic and falciform ligament. ${ }^{77}$ Anatomically, the membranous superficial fascia creates a tube like conduit attaching to a ring of the external oblique aponeurosis, umbilicus, and skin. ${ }^{59}$

The different types of discoloration of the umbilicus varying from bluish to yellow-green or orange, as reported by Novak, reflected the "differing degrees of oxidation of the deposited blood pigment" over time. ${ }^{78}$ Thus, bluish discoloration suggests a recent hemorrhage, while the yellow-green to orange discoloration reflects a more distant hemorrhage.

In a study of 410 cases of ectopic pregnancy, Lavell reported that Cullen sign was rare, occurring twice in the same patient who had two ectopics. ${ }^{79}$ Behney, in 167 consecutive cases of ectopic pregnancy, reported the presence of Cullen sign in one patient. ${ }^{80}$ Additionally, in a review of 90 cases of extrauterine pregnancy, Jonas did not find a single patient with Cullen sign. ${ }^{81}$ In a prospective cohort study involving 770 patients between 1971 and 1983, it was reported that nine patients (1.1\%) had Grey Turner sign, nine $(1.17 \%)$ Cullen, and five $(0.65 \%)$ had both signs with an associated mortality of $37 \% .{ }^{82}$ Given the rarity of this sign, it lacks sufficient sensitivity and specificity in diagnosis. ${ }^{76}$

\section{Tanyol Sign}

Hasib Tanyol (1916-1999) was born in Eskisehir, Turkey. He graduated from Istanbul University Faculty of Medicine and completed internships at the University of Vienna and University of Freiburg, Germany. ${ }^{83}$ He served in the Division of Gastroenterology at the Jefferson Medical College of Philadelphia from 1951 to 1955 . Dr. Tanyol was a preceptor in the Department of Anatomy and Assistant Professor of Medicine at Hahnemann Medical College in 1966, eventually receiving dual professorships at Thomas Jefferson University and Hahnemann University in Philadelphia. He devoted much of his career to the study of liver cirrhosis and the vascular aspects of cirrhosis of the liver and hypertension. ${ }^{84} \mathrm{He}$ maintained a practice in Fort Washington and Lafayette Hill, serving on the medical staff of Germantown Hospital and Montgomery Hospital in Norristown Philadelphia.

In cirrhotic patients without ascites or obesity, and age and race matched controls without hepatic disease, Tanyol (1956) describe the method for identifying umbilical ptosis:

"In measuring the distance from the midumbilicus to the lower end of the xiphoid process and to the upper edge of the symphysis a tape-measure was used. The ratio of the upper to the lower distance may be referred to as the "umbilical index." 85 (p.418, emphasis added)

He found "in noncirrhotic individuals the distance from the umbilicus to the xiphoid process is almost equal to the distance from the umbilicus to the symphysis. In cirrhotic patients, however the upper distance is much greater than the lower." 85 (p.422-423, emphasis added) Thus, according to Tanyol, the term "umbilical ptosis" is employed to designate a marked lengthening of the distance between the xiphoid process and the umbilicus, which appears to be a little-recognized sign of portal cirrhosis. ${ }^{85}$ In ascites, the distance between the xiphoid and umbilicus is more than the distance between the umbilicus and symphysis pubis. ${ }^{85}$ It is of historical interest that in 1922 Chvostek $^{86}$ identified an umbilical hernia to be another constitutional sign of cirrhosis.

Tanyol (1956) described the relationship between umbilical ptosis and other manifestations of cirrhosis:

It is not within the scope of this paper to discuss the mechanism by which cirrhosis and umbilical ptosis are related. The occurrence of umbilical ptosis in association with other manifestations of 'static disorders of the connective tissue', such as hernia, varicose veins, cutaneous phlebectasia, varicocele, and hemorrhoids, in patients with cirrhosis has been demonstrated elsewhere; it has been emphasized that, in contrary to the prevailing view, the latter stigmata precede the development of ascites of portal hypertension by many years. ${ }^{85}$ (p.422, emphasis added)

The sensitivity and specificity of Tanyol sign has not been studied. Given its finding in other diseases, we suspect that Tanyol sign may be a sensitive but non-specific sign for diagnosing cirrhosis.

\section{Fox Sign}

There is limited information available about Dr. JA Fox, MB, FRCS. He served as Senior Surgical Registrar, the Royal Free and Royal Northern Hospital, London and subsequently took a position as a Consultant Surgeon at Edgware General Hospital, Middlesex, United Kingdom. ${ }^{87}$

Fox described his findings in two patients in 1966. In his first patient with acute suppurative pancreatitis he found:

Fourteen hours after admission bruising was noted in 
both upper outer thighs. It had a sharp upper margin, was blue, and was quite distinct from the patchy mottling of her legs below. ${ }^{87}$ (p.193, emphasis added)

In the second patient with dissecting and ruptured abdominal aortic aneurysm, "Before death bruising was noticed in the upper outer aspect of one thigh." 87 (p.193, emphasis added)

This sign, described in these two patients refers to the blue discoloration of the upper thigh that extended along a horizontal line corresponding to the lower limit of the membranous superficial fascia attachment to the fascia lata of the thigh. ${ }^{59}$ Thus, this sign represents ecchymosis of the inguinal ligament caused by retroperitoneal hemorrhage.

Fox (1966) described the mechanism of this finding:

Careful examination of the bruised area shows a wellmarked upper limit. This straight line runs parallel to and below the inguinal ligament. It corresponds to the attachment of the membraneous layer of the superficial fascia (Scarpa's fascia) to the fascia lata ligament, but below its attachment the bruising is more rapidly developed. ${ }^{87}$ (p.194, emphasis added)

Scarpa's fascia can be thought of as arising from the fascia lata about $1 / 2$ inch below the inguinal ligament and, sweeping upwards over this ligament, is a thin membrane, fibrous in nature and of considerable strength. This sign is a rare clinical finding that lacks sufficient sensitivity and specificity in diagnosis.

\section{Markle Sign}

George Bushar Markle, IV (1921-1999) was born in Hazleton, Pennsylvania, completed undergraduate training at Yale University and received his medicine degree from University of Pennsylvania Medical School in 1946. He was a diplomate of the American Board of Surgery and practiced surgery in Carlsbad, New Mexico for most of his career. ${ }^{88}$

Markle's sign, also known as the heel-drop jarring test is a variation of the rebound tenderness test, is elicited by:

The patient is asked to stand knees straight, with or without shoes. The clinician faces him and asks the patient to do as he does. The clinician stands on his toes for a few seconds and, relaxing suddenly, comes down with his full weight upon his heels with a definite thump. The unsuspecting patient does likewise and may be quite surprised to feel a definite pain wherever there is inflammation in the abdomen. Not only can he tell you, usually quite positively, if there is pain, but also he can tell just where the pain is most severe. In the wary patient who bends the knees or who comes down on the heels too gently, it may be necessary to repeat the test with admonitions to the patient not to restrain his short drop. ${ }^{89}$ (p.721, emphasis added)

He reported, in 43 patients with confirmed appendicitis, rebound tenderness in $86 \%$, a positive sign in $93 \%$, and in those with a positive sign $92 \%$ identified the exact location of their underlying disease. ${ }^{89}$ In another study, $74 \%$ of 190 patients with acute appendicitis had a positive sign with $71 \%$ identifying the precise localization of the inflammation..$^{90} \mathrm{Ahn}$ et $\mathrm{al}^{91}$ comparing Markle sign with rebound tenderness, reported a sensitivity and specificity for Markle sign of $69 \%$ and $65 \%$, respectively, and for rebound tenderness to be $59 \%$ and $63 \%$, respectively. The odds ratio for Markle sign was 3.43 , higher than any other factor evaluated in this study for diagnosing appendicitis. ${ }^{91}$ Mentes et $\mathrm{al}^{92}$ showed that a positive Markle sign has a sensitivity and specificity of $85 \%$ and $30 \%$, respectively, and odds ratio for a positive Markle sign of 2.5. A positive Markle sign combined with an elevated white blood cell count $\left(\geq 11.9 / \mathrm{mm}^{3}\right)$ and pain in the right lower quadrant increased the odds ratio to 9.75 with a positive predictive value to $96 \%$ in diagnosing appendicitis..$^{92}$ Thus, Markle sign is a useful bedside test in detecting acute appendicitis; however, the absence of this sign does not exclude the diagnosis of abdominal inflammation.

\section{Dunphy Sign}

John Englebert Dunphy (1908-1981) was born in Northampton, Massachusetts. He received his medical degree from Harvard Medical School in 1933. ${ }^{93,94}$ In 1939, he was a faculty member in the Department of Surgery at Harvard Medical School and practiced surgery at Newton-Wellesley area.

In 1955, he was appointed Professor of Surgery at Harvard and became the first director of the Fifth (Harvard) Surgical Service of the city of Boston and the Sears Surgical Laboratories in Boston City Hospital. In 1959, he left Boston to serve as the Kenneth H.A. MacKenzie Professor of Surgery and Chairman of the Department of Surgery at the University of Oregon..$^{95}$ In 1964, he served as professor and Chairman of the Department of Surgery at University of California San Francisco (UCSF), where he developed the trauma center and trauma research program. His work and research interest spanned many fields including wound healing, teaching, diplomacy, and care of the dying patient. He served as chairman of the American Board of Surgery, Board of Regents of the American College of Surgeons, ${ }^{95}$ and he received ten honorary degrees including honorary fellowship in six Royal Colleges. ${ }^{94}$

Dunphy (1975) wrote in his book Physical Examination of the Surgical Patient:

The patient should first be asked to cough. In the presence of acute peritoneal inflammation this usually elicits a sharp twinge of pain localized to the involved area. It is extremely valuable to elicit this "cough tenderness" and have the patient point with one finger to the exact area of pain. This localizes the area of inflammation before the examiner so much as touches the patient. He can thus avoid palpating this area until the remainder of the abdominal examination is completed. ${ }^{96}$ (p.147, emphasis added)

In a prospective study of 100 consecutive patients presenting with right lower quadrant pain, 44 patients were found to have histologically confirmed appendicitis, and 14 had a normal appendix. The sensitivity, specificity, positive predictive value, 
and accuracy of the cough test was $82 \%, 52 \%, 56 \%$, and $64 \%$, respectively. ${ }^{97}$ In a cohort study involving 866 patients, the sensitivity and specificity of the cough test was $95.1 \%$ and $80 \%$, respectively. ${ }^{98}$ In an evaluation of 143 patients with peritonitis, sensitivity, specificity, positive predictive values, and odds ratio for the cough test of $78 \%, 79 \%, 76 \%$, and 13.2 , respectively, were reported. ${ }^{99}$ Dixon, respectively identified an odds ratio of 1.42 for pain caused by coughing in patients with acute appendicitis. ${ }^{100}$ Therefore, a negative cough test is not sufficiently reassuring in excluding the diagnosis of appendicitis.

\section{Bapat's Bed Shaking Test}

Ravindra (Ravi) Dinkar Bapat (1942-) is Professor Emeritus of Surgical Gastroenterology in the Department of Gastroenterology Surgical Services, Seth G.S. Medial College and KEM Hospital, Parel, Mumbai. He served as Vice Chancellor, Mahatma Gandhi Mission University of Health Sciences and Vice-Chancellor, Maharashtra University of Health Sciences. His research interests are in the areas of surgical jaundice and pancreatitis. ${ }^{101}$ Dr. Bapat is the recipient of numerous awards for his service and outstanding contributions to teaching in the field of gastroenterology. ${ }^{102,103}$

We were unable to identify the original source of this sign. The test is used to elicit and confirm whether inflammation of the peritoneum is the source of pain. According to Prabhu, ${ }^{10}$ the test is performed by "gently shaking the bed." A positive test is when the patient complains of pain. ${ }^{64}$ In 1874, Meade, in his chapter on "Diseases of the peritoneum" in the book Meade's Manual for Students Preparing for Medical Examination, wrote "In most cases the pain is severe and tenderness excessive; every movement is dreaded-even a footstep which may shake the bed excites apprehension." "103 (p.135, emphasis added)

Herrick described in 1906:

Surely a palpation and percussion of the abdomen sufficient to test for fluctuation, or a shaking of the patient, or, better still, of the bed, to bring out succession is a far safer and more rational procedure than an exploratory puncture for suspected appendicular abscess or localized peritoneal exudate from other causes. ${ }^{104}$ (p.925, emphasis added)

It is of interest that Leigh, in 1908, described the transportation of patients with appendicitis with peritoneal inflammation:

Both on railway trains and on vehicles, there is necessarily a certain amount of unavoidable shaking of the patient. If there is free pus in the peritoneal cavity, it will be distributed around in every direction. If an abscess has been walled off, its adhesions may be broken down by the shaking. In any case, it is exceedingly important that the patient during transportation be kept in such a position that the pus be not spread around, but be kept as near its original focus as possible. I believe that much harm is done to these patients by our ordinary city ambulances and rough streets. ${ }^{105(\mathrm{p} .463)}$
The test is considered more humane than repeat palpation of the abdomen in patients with peritonitis. We are unaware of any studies that evaluated the sensitivity and specificity of this sign for the diagnosis of peritonitis.

\section{Conclusion}

Eponyms ascribed to abdominal signs of inspection are small contributions that these physicians made to the field of medicine and surgery. Medical eponyms assigned to clinical signs of the abdomen are used in clinical practice despite their consistent lack of validity. For the few sign that have been studied, they often lack sufficient diagnostic sensitivity, specificity, and predictive values. A notable exception is Beevor sign in patients with fasciohumeral muscular dystrophy. Despite these limitations, these signs are elicited by some clinicians and in some cases often depart from their original description, as in Kehr sign. Further studies, especially those with large study samples, are required to evaluate the validity of these bedside tests.

\section{References}

1. Jana N, Barik S, Arora N. Current use of medical eponyms - a need for global uniformity in scientific publications. BMC Med Res Methodol. 2009;9(1):18.

2. Ferguson RP, Thomas D. Medical eponyms. J Community Hosp Intern Med Perspect. 2014;4(3):25046.

3. Skinner HA. The Origin of Medical Terms. Baltimore: Williams \& Wilkins Co; 1949. 177.

4. Coxe JR. The Book of Prognostics. The Writings of Hippocrates and Galen. Epitomised from the original Latin translations, by Member of the Batavian Society of Sciences at Harlem; of the Royal Medical Society, and the Royal Society of Sciences of Copenhagen, etc. Philadelphia: Lindsay and Blakiston; 1846. 87.

5. Blumgart HL. Editorial. Leopold Auenbrugger. His “inventum novum"-1761. Circulation. 1961;24(1):1-4.

6. Smith JJ. The Inventum Novum of Joseph Leopold Auenbrugger. Bull N Y Acad Med. 1962;38(10):691-701.

7. Bedford DE. Auenbrugger's contribution to cardiology. History of percussion of the heart. Heart. 1971;33(6):817-821.

8. Auenbrugger L. (1722-1809). Text and Documents On percussion of the chest being a translation of Auerbrugger's original treatis entitled "Inventum novum ex percussione thoracis humani, ut singo abstrsos interni perctoris morbos detegendi.". [Vienna, 1761] Translation by John Forbes, Introduction by Henry E. Sigerist. London: The Johns Hopkins Press; 1824. 373-403.

9. White FA. Physical Signs in Medicine and Surgery, An Atlas of Rare, Lost and Forgotten Physcial Signs. Includes a Collection of Extraordinary Papers in Medicine, Surgery and the Scientific Method. Glasgow: Museum Press Books; 2009.

10. Prabhu S. Clinical Signs \& Syndromes in Surgery. Jaypee Brothers Medical Publisher Ltd.: Bengaluru, India; 2011.

11. Dance JBH. Committee on historical and scientific works. 02/26/2011-France learned. Available at: http://cths.fr/an/ savant.php?id=105491. Accessed March 5, 2019.

12. Dance JBH. Mémoire sur les invaginations morbides des intestins. In: Répertoire général d'anatomie et de physiologie pathologiques, et de clinique chirurgicale, ou Recueil de mémoires et d'observations sur la chirurgie, et sur l'anatomie et la physiologie considérées dans les tissue sains et le tissus malades. Tome Premier. Paris: Chez Boiste; 1826:195-214.

13. D'Agostino J. Common abdominal emergencies in children. Emerg Med Clin North Am. 2002;20(1):139-153. 
14. Sty JR, Babbitt DP, Boedecker RA. Radionuclide??? Dance Sign??? Clin Nucl Med. 1980;5(11):502-503.

15. Firkin BG, Whitworth JA. Dictionary of Medical Eponyms. Boca Raton: The Parthenon Publishing Group, A CRC Press Company; 2002.

16. Kehr H. Die Praxis der Gallenwege-Chirurgie in Wort und Bild. Die Vorbereitungen zu einer Operation an den Gallenwegen und die allgemeine Technik der Gallenwege-Chirurgie. München: J.F. Lehmann's Verlag; 1913.

17. Klimpel V. [Does Kehr's sign derive from Hans Kehr? A critical commentary on its documentation?]. Chirurg. 2004;75(1):8083. [Article in German]

18. Kehr H. Introduction to the Differential Diagnosis of the Separate Forms of Gallstone Disease based upon His own experience gained in 433 laparotomies for gallstones. Authorized translation by William Wotkyns Seymour, AB, Yale, M.D., Harvard. With an introduction by Prof. Kehr. Philadelphia, Blakiston's Son \& Co. 1901.

19. Lowenfels AB. Kehr's sign - a neglected aid in rupture of the spleen. N Engl J Med. 1966;274(18):1019.

20. Sutton CD, Marshall LJ, White SA, Berry DP, Dennison AR. Kehr's sign - a rare cause: Spontaneous phrenic artery rupture. ANZ J Surg. 2002;72(12):913-914.

21. Söyüncü S, Bektaş F, Cete Y. Traditional Kehr's sign: Left shoulder pain related to splenic abscess. Ulus Travma Acil Cerrahi Derg. 2012;18(1):87-88.

22. Skipworth JRA, Raptis DA, Rawal JS, et al. Splenic injury following colonoscopy - an underdiagnosed, but soon to increase, phenomenon? Ann R Coll Surg Engl. 2009;91(4):W6 11.

23. Shah PR, Raman S, Haray PN. Splenic rupture following colonoscopy: Rare in the UK? Surgeon. 2005;3(4):293-295.

24. Sachdev S, Thangarajah H, Keddington J. Splenic rupture after uncomplicated colonoscopy. Am J Emerg Med. 2012;30(3):515.e1-515.e2.

25. Steele DC, Mohamed AM, Kaza A, McCarthy D. Splenic rupture following colonscopy. Dig Dis Sci. 2017;62(1):72-75.

26. Bonsignore A, Grillone G, Soliera M, et al. [Occult rupture of the spleen in a patient with infectious mononucleosis]. G Chir. 2010;31(3):86-90 [Article in Italian]

27. Obituary. Charles Edward Beevor, M.D. Lond, M.R.C.S Eng, F.R.C.P. Lond, Physician to the National Hospital for the Paralysed and Epileptic and to the Great Northern Central Hospital, etc. Lancet. 1908;2(2):1854-1855.

28. Obituary. Charles Edward Beevor M.D., F.R.C.P.Lond., Physician, National Hospital for the Paralyzed and Epileptic. Br Med J. 1908;2:1785.

29. O’Connor WJ. British Physiologist 1885-1914: A Biographical Dictionary. Neurologist at the National Hospital, Honorary lecturer in Physiology, University of Leeds. In: W.K. O'Connor ed. Manchester and New York. USA and Canada by St. Martin's Press, New York: Manchester University Press; 1991.

30. Beevor CE. The Croonian Lectures on muscular movements and their representation in the central nervous system. Movement of the Spinal Column. Delivered before the Royal College of Physicians of London on June 1903 by Charles E Beevor MD Lond, FRCP. Physician to the national hospital for the paralysed and epileptic, Queen Square and to the Great Northern Central Hospital. London Adlard ad Son. Bartholomew Close 1904:39-45.

31. Mills CK. Tumors and Cysts of the Spinal Cord and Its Envelopes, Reports of Societies. The American Neurological Association 36 Annual Meeting May 2,3 and 4, 1910. Monday Session. Boston Med Surg J. 1910;63:62-64.

32. Hilton-Jones D. Beevor's sign. Pract Neurol. 2004;4(3):176177.
33. Awerbuch GI, Nigro MA, Wishnow R. Beevor's sign and facioscapulohumeral dystrophy. Arch Neurol. 1990;47(11):1208-1209.

34. Shahrizaila N, Wills AJ. Significance of Beevor's sign in facioscapulohumeral dystrophy and other neuromuscular diseases. J Neurol Neurosurg Psychiatry. 2005;76(6):869-870.

35. Eger K, Jordan B, Habermann S, Zierz S. Beevor's sign in facioscapulohumeral muscular dystrophy: an old sign with new implications. J Neurol. 2010;257(3):436-438.

36. Leon-Sarmiento FE, Bayona EA, Bayona-Prieto J. A sudden Beevor's sign. Clin Med Res. 2007;5(2):121-122.

37. Sugie K, Kumazawa A, Ueno S. Sporadic inclusion body myositis presenting with Beevor's sign. Intern Med. 2015;54(21):2793-2794.

38. Preethish-Kumar V, Pogoryelova O, Polavarapu K, et al. Beevor's sign: a potential clinical marker for GNE myopathy. Eur J Neurol. 2016;23(8):e46-e48.

39. Milisenda JC, Rico Caballero V, García AI, Tomás X, Grau JM. «Extended» Beevor's sign as a new clinical sign in sporadic inclusion body myositis. Med Clin (Barc). 2017;148(8):e43.

40. Quinquennial Catalogue of the Officers and Graduates by Harvard University 1636-1910, Cambridge Massachusetts, Published by the University in two hundred and seventyfourth year of the College. The University Press: Cambridge, MA, USA; 1910.

41. Harvard College Class of Nineteen one, Second Report-June 1907. The University Press; Cambridge, MA, USA; 1907.

42. Secretary's Fourth Report by Harvard College Class of 1901, July 1916. Cambridge, MA, USA; Crimson Printing Company; 1916.

43. Ransohoff J. Gangrene of the gall bladder. Rupture of the common bile duct, with a new sign. JAMA. 1906;XLVI(6):395-397.

44. Columbia University Quarterly. Volume VI. Matthews B., eds. New York: Columbia University Press; 1903-1904. 6: 71.

45. Columbia University Bulletin of Information. Catalogue and General Announcement 1907-1908. Catalogue of the Officers and Students of Columbia College. Columbia University in the City of New York. Morningside Heights, New York; 1907-1908.

46. Columbia Alumni News. Levering Tyson. 1916;7:541.

47. Medical News. JAMA. 1919;73:435.

48. Andresen AF. Dr. Walter Arthur Bastedo, 1873-1952. Gastroenterology 1953;25:91-92.

49. Medical Record: a Journal of Medicine and Surgery. In: Stedman TL, ed. Wood \& Co: New York; 1921. 488.

50. Deaths. Walter Arthur Bestedo .JAMA. 1952;150:233-234.

51. Bastedo WA. Artificial dilation of stomach and colon as aids in abdominal diagnosis; with a helpful sign in chronic appendicitis. St. Luke's Hospital Medical and Surgical Reports. 1910;2:104-111.

52. Bischoff CW. Differentialdiagnose der Appendicitis chronica. Monatsschr Geburtshulfe Gynakol. 1914;40:398-404.

53. Hertz AF. Bastedo's Sign: a New Symptom of Chronic Appendicitis. Proc R Soc Med. 1913;6(Clin Sect):185-188.

54. Welbourn RB. George Grey Turner, 1877-1951. Centenary Celebration at the Royal Postgraduate Medical School. Ann R Coll Surg Engl. 1978;60(4):298.

55. White H. An outstanding ISS/SIC surgeon: George Grey Turner. World J Surg. 2003;27(5):511-513.

56. Turner GG. Local discoloration of the abdominal wall as a sign of acute pancreatitis. Br J Surg. 1919;7(27):394-395.

57. Bosmann M, Schreiner O, Galle PR. Coexistence of Cullen's and Grey Turner's signs in acute pancreatitis. Am J Med. 2009;122(4):333-334.

58. Meyers MA, Feldberg MAM, Oliphant M. Grey Turner's sign and Cullen's sign in acute pancreatitis. Gastrointest Radiol. 1989;14(1):31-37. 
59. Ullah SM, Grant RC, Johnson M, McAlister VC. Scarpa's fascia and clinical signs: the role of the membranous superficial fascia in the eponymous clinical signs of retroperitoneal catastrophe. Ann R Coll Surg Engl. 2013;95(7):519-522.

60. Fan Z, Zhang Y. Grey Turner's and Cullen's signs induced by spontaneous hemorrhage of the abdominal wall after coughing. Ann Surg Treat Res. 2017;93(2):115-117.

61. Rao A, Swathi T, Farheen S, et al. Desmoid tumor of rectus abdominis presenting with Grey-Turner's and Cullen's Sign: A report of a rare case. Indian J Dermatol. 2017;62(3):318-320.

62. Sonmez BM, Yilmaz F, Özkan FB, Ongar M, Özturk D, Cesur F. Retroperitoneal haematom due to spontaneous rupture and haemorrhage of adrenal cyst presenting with Grey Turner's sign. J Pak Med Assoc. 2015;65(7):788-789.

63. Argiriou M, Xydonas S, Filippatos G. Grey-Turner sign after intra-aortic balloon pump insertion. Intern Med J. 2006;36(11):750-751.

64. Morbidity of acute pancreatitis: the effect of aprotinin and glucagon. Gut 1980;21(4):334-339.

65. Koizumi M, Takada T, Kawarada Y, et al. JPN Guidelines for the management of acute pancreatitis: diagnostic criteria for acute pancreatitis. J Hepatobiliary Pancreat Surg. 2006;13(1):25-32.

66. Thomas Stephen Cullen. Portrait Collection. The Johns Hopkins Medical Institution. Available at: https://portraitcollection. jhmi.edu/portraits/cullen-thomas-stephen. Accessed March 5, 2019.

67. The Thomas S. Cullen Collection. The Alan Mason Chesney medical Archives of The Johns Hopkins Medical Institutions. Available at: https://medicalarchives.jhmi.edu:8443/papers/ cullen.html. Accessed March 5, 2019.

68. Te Linde RW. Thomas Stephen Cullen. Am J Obstet Gynecol. 1953;66(2):462-464.

69. Cullen TS. A new sign in ruptured extrauterine pregnancy. Am J Obstet Gynecol. 1918;78:457.

70. Sajous CE, Jelliffe SE. Proceedings of National and Local Societies, The American Gynecological Society, 43rd Annual Meeting, Philadelphia, May 16-18, 1918. The New York Medical Journal, incorporating The Philadelphia Medical Journal and the Medical News: a Weekly Review of Medicine. A.R. Elliot Publishing Company: New York; 1918.

71. Editorial. Cullens' sign in ruptured ectopic pregnancy. JAMA. 1935; 104(20):1828.

72. Kapsinow R. Cullen's sign in conditions other than extra-uterine pregnancy. JAMA. 1925;84(15):1107.

73. Merrill JA. Cullen's sign; a historical review and report of histologic observations. Obstet Gynecol. 1958;12(3):317-324.

74. Johnston LB. Acute hemorrhagic pancreatitis: A case presenting yellow discoloration at the umbilicus. JAMA. 1930;95(21):1587-1588.

75. Fallis LS. Cullen's sign in acute pancreatitis. Ann Surg. 1937;106(1):54-57.

76. Smith I, Wright FJ. Cullen's sign in ruptured gestation with a report of two cases. Lancet. 1935;225(5825):930-932.

77. Rahbour G, Ullah MR, Yassin N, Thomas GP. Cullen's sign Case report with a review of the literature. Int J Surg Case Rep. 2012;3(5):143-146.

78. Novak E. Bluish discoloration of the umbilicus in the diagnosis of ruptured extrauterine pregnancy. JAMA. 1922;78(9):643.

79. Lavell TE. The diagnosis of ectopic gestation (410 cases). Am J Obstet Gynecol. 1929;18:379-392.

80. Behney CA. Extra-uterine pregnancy: study of one hundred sixty-seven consecutive cases. JAMA. 1930;95(21):15571563.

81. Jonas AF Jr. Evaluation of signs and symptoms in diagnosis of extrauterine pregnancy. N Engl J Med. 1933;209(26):13241328.
82. Dickson AP, Imrie CW. The incidence and prognosis of body wall ecchymosis in acute pancreatitis. Surg Gynecol Obstet. 1984;159(4):343-347.

83. Tanyol H. Available at: https:/www.findagrave.com/ memorial/54781305/hasib-tanyol. Accessed September 1, 2017.

84. Proceedings of the American Association of Anatomists 76th annual meeting. Georgetown University School of Medicine, Washington, DC. April 9-11, 1963. 389.

85. Menduke $\mathrm{H}$, Tanyol H. Umbilical ptosis; frequent physical sign in portal cirrhosis. Am J Dig Dis. 1956;1(10):417-423.

86. Chvostek F. Zur Pathogenese der Leberzirrhose. Wien Klin Wochenschr. 1922;35:381-408.

87. Fox JA. A diagnostic sign of extraperitoneal haemorrhage. Br J Surg. 1966;53(3):193-195.

88. Obituaries. Dr. George Bushar Markle IV, native of Hazelton, dies. Hazelton Standard-Speaker, Pennsylvania. October 13, 1999. Available at: https://www.newspapers.com/ clip/11629375/standardspeaker/. Accessed September 1, 2017.

89. Markle GB 4th. A simple test for intraperitoneal inflammation. Am J Surg. 1973;125(6):721 722.

90. Markle GB 4th. Heel-drop jarring test for appendicitis. Arch Surg. 1985;120(2):243.

91. Ahn S, Lee H, Choi W, et al. Clinical importance of the heel drop test and a new clinical score for adult appendicitis. PLoS One. 2016;11(10):e0164574.

92. Mentes O, Erylmaz M, Coskun K, Harlak A, Ozer T, Kozak O. The importance of heel drop physical examination sign in diagnosis of acute appendicitis. European Journal of Surgical Sciences. 2010;1(13):77-82.

93. United Press International. 1981. Dr. J Englebert Dunphy, an international known surgeon at... Available at: https://www. upi.com/Archives/1981/12/25/Dr-J-Englebert-Dunphy-aninternationally-known-surgeon-at/6739378104400/. Accessed September 1, 2017.

94. Callisphere. University of California: In Memoriam, 1986. John Englebert Dunphy, Surgery: San Francisco. Available at: http://texts.cdlib.org/ view?docId=hb767nb3z6;NAAN=13030\&doc. view $=$ frames\&chunk.id=div00029\&toc.depth $=1 \&$ toc. $\mathrm{id}=\&$ brand=calisphere. Accessed September 1, 2017.

95. Nunes GC. The legacy of J. Englebert Dunphy. Am J Surg. 1995;169(5):466-470.

96. Dunphy JE, Botsford TW. Physical Examination of the Surgical Patient. An Introduction to Clinical Surgery. Examination of the abdomen. III. The appraisal of abnormal findings Philadelphia: WB Saunders Company; 1975. 136146.

97. Golledge J, Toms AP, Franklin IJ, Scriven MW, Galland RB. Assessment of peritonism in appendicitis. Ann R Coll Surg Engl. 1996;78(1):11-14.

98. Idris SA, Shalayel MH, Awad YO, Idris TA, Ali AQ, Mohammed SA. The sensitivity and specificity of the conventional symptoms and signs in making a diagnosis of acute appendicitis. Sudan Journal of Medical Sciences. 2009;4(1):55-61.

99. Bennett HD, Tambeur LJ, Campbell WB. Use of coughing test to diagnose peritonitis. BMJ. 1994;308(6940):1336.

100. Dixon JM, Elton RA, Rainey JB, Macleod DA. Rectal examination in patients with pain in the right lower quadrant of the abdomen. BMJ. 1991;302(6773):386-388.

101. Bapat R, Bhate K. Know Your Ailment: A Ready Reckoner. Indus Source Books: Mumbai, India; 2017. Available at: http://www.esamskriti.com/essays/pdf/15-know-yourailment-indus-source.pdf. Accessed September 1, 2017. 
102. Gosumec Alumni Association. Notable Alumni Dr. Ravi Bapat. Available at: https://www.facebook.com/gosumecgsmc/ alumini-details/502. Accessed September 1, 2017.

103. Silver A. Diseases of the Peritoneum. In: Renshaw H, ed. Practical Medicine with a Sketch of Physiology and Therapeutics Being. Meade's Manual for students. 4th ed. London: Savill, Edwards and Co.; 1874. 134-147.

104. Herrick JB. Acute dilation of the stomach with report of two cases, one of which complicated pneumonia and ended in recovery. JAMA. 1906;XLVI(13):923-926.

105. Leigh S. Treatment of diffuse suppurative peritonitis. Virginia Medical Semi-Monthly. 1908;12:461-463.

\section{Author Affiliations}

Vaibhav Rastogi, MD*; Devina Singh, MD ; Halil Tekiner,

PhDf; Fan Ye, MD*; Joseph J. Mazza, MD\&; and Steven H. Yale, $M D \|$

*University of Central Florida College of Medicine, Graduate Medical Education, 6850 Lake Nona Blvd, Orlando, Florida

†University of Florida, Department of Medicine. 2000 SW Archer Rd, Gainesville, Florida

Erciyes University School of Pharmacy, Department of the History of Pharmacy and Ethics. Talas, Kayseri, Turkey \$Marshfield Clinic Research Institute, 1000 North Oak Avenue, Marshfield, Wisconsin \|University of Central Florida College of Medicine, Department of Internal Medicine, 6850 Lake Nona Blvd, Orlando, Florida. 